Volume 10. No.2, February 2022

International Journal of Emerging Trends in Engineering Research

Available Online at http://www.warse.org/IJETER/static/pdf/file/ijeter061022022.pdf

https://doi.org/10.30534/ijeter/2022/061022022

\title{
Automatic Distance and Angle Measurement Tool using Atmega8535 Microcontroller based Ultrasonic Sensor for Conventional X-Ray Medical Device
}

\author{
Ari Murtanto ${ }^{1}$, Budi Santoso ${ }^{2}$, Pahriansyah $^{3}$, Novi Azman $^{4 *}$ \\ ${ }^{1}$ Engineering and Science Faculty, Universitas Nasional, Indonesia, ari.murtanto@civitas.unas.ac.id \\ ${ }^{2}$ Engineering and Science Faculty, Universitas Nasional, Indonesia, budi.santoso@civitas.unas.ac.id \\ ${ }^{3}$ Engineering and Science Faculty, Universitas Nasional, Indonesia, pahriansyah@ @ivitas.unas.ac.id \\ ${ }^{4}$ Engineering and Science Faculty, Universitas Nasional, Indonesia, \\ novi.azman@civitas.unas.ac.id (corresponding author)
}

Received Date : December 31, 2021 Accepted Date : January 26, 2022 Published Date : February 07, 2022

\begin{abstract}
The aim of this research is to design an ultrasonic distance and angel detecting device by utilizes time delay of wave reflected. The ultrasonic echo waves were then converted into electrical echo pulses. This distance and angle detecting device can later be used on conventional X-ray modality. This distance and angle detecting device was designed based on ultrasonic sensor and an Atmega8535 microcontroller. Distance measurements was carried out vertically and horizontally with variations ranging from $90 \mathrm{~cm}$ to $130 \mathrm{~cm}$ with a $10 \mathrm{~cm}$ increment factor. While angle measurements were performed manually at angle variations of $10^{\circ}$ to $30^{\circ}$ with an increment factor of $5^{\circ}$. The performance of the tool showed that the relative error value on vertical measurement was $0.10 \%$ with the greatest accuracy of $99.97 \%$. While the horizontal measurement relative error was $0.10 \%$ and the highest relative accuracy recorded at $99.97 \%$. Meanwhile, on the angle measurement, it was found that the relative error was $0.39 \%$ with the highest relative accuracy of $99.72 \%$.
\end{abstract}

Key words: Atmega8535, measuring instrument, ultrasonic sensor, X-Ray.

\section{INTRODUCTION}

Measurement is important in the world of science and in life, including measuring distance from one place to another, measuring time from one event to another, measuring temperature, the temperature of one area to another, measuring the angle from a point. to a specific object point [1]-[4]. In general, to measure the distance from one point to another, a ruler or meter can be used. Along with the times and increasingly sophisticated technology, to measure distances and angles from one point to another, ultrasonic waves can be used [5]-[8]. By utilizing the ultrasonic waves that are emitted and received, the distance and angle measurements can be read automatically.

\section{CONVENTIONAL X-RAY PLANE}

A conventional X-ray machine is one type of X-ray machine used for radiography. The meaning of conventional here, shows the type of aircraft in terms of movement, where this conventional aircraft movement is limited to stationary and can only be used in a room that has been specially designed for this X-ray aircraft, it is different with mobile X-ray aircraft which can be placed in carry or move from one place to another, but all types of $\mathrm{X}$-ray equipment have advantages and disadvantages. In the world of radiology, there are many kinds of tools that are used to carry out an examination, one of which is a conventional X-ray machine [9], [10].

\section{SHOOTING DISTANCE}

In the radiographic technique, the distance between the tube and the film is divided into 3 parts, namely FOD, FFD, OFD as shown in Figure 1 [11], [12].
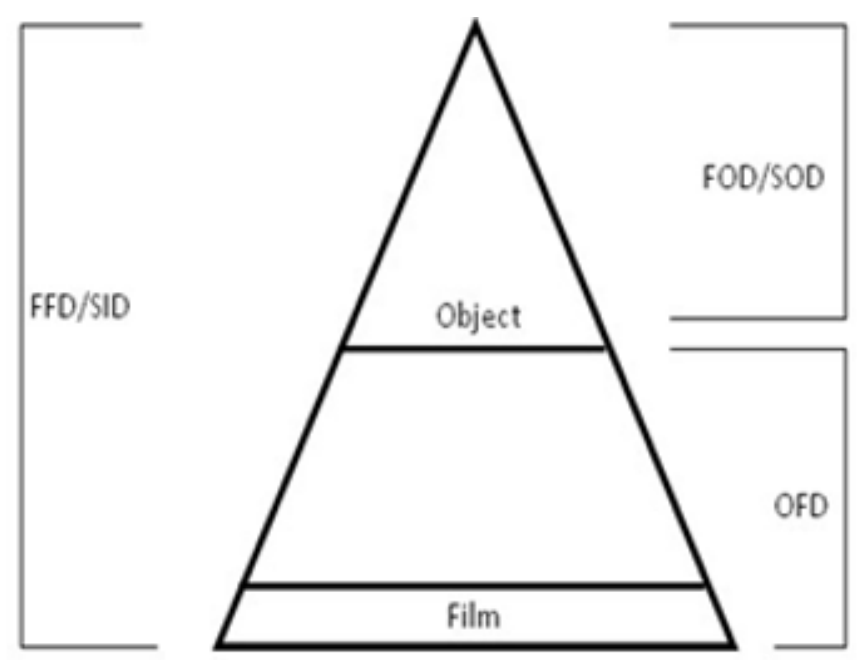

Figure 1: FDD, FOD, and OFD 
Explanation of Figure 1 is below [13]-[16].

1.FFD (Film Focus Distance)/SID (Source Image Distance)

This term is given to the distance from the focus located on the window in the tube to the surface of the film.

2. FOD (Film Object Distance)/SOD (Source Object Distance)

This term is given to the distance from the focus that is on the window on the tube to the object point.

3. OFD (Object Film Distance)

This term is given to the distance from the object of interest to the surface of the film.

In addition to determining the distance when conducting an inspection, on the other hand, there is also an angle technique or determining the degree of inclination at the time of the inspection. This angle technique also plays an important role in radiology as a diagnostician. To determine the angle, there are several techniques, including being able to angle or position the patient directly according to the photo request in the form, it can also be by tilting the cassette by propping it with foam or the like so that the desired angle is formed, it can also be by angling the $\mathrm{X}$-ray tube. by rotating the tube according to the desired angle. The following is an example of an examination technique using an angle which can be seen in Figure 2.

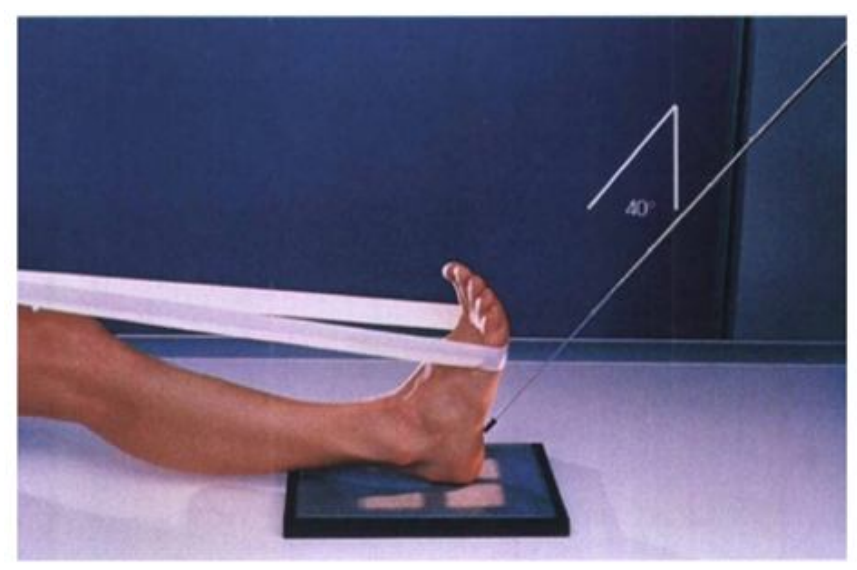

Figure 2: Cornering Technique

\section{RESEARCH METHODOLOGY}

The design of this research is a design to produce an automatic distance and angle measuring instrument with an ultrasonic sensor on a conventional X-ray aircraft. It is hoped that this examination tool will make it easier for the radiographer to carry out the examination. The assembly of tools was carried out in various places, namely at the Electronics Laboratory of the National University. The instrument testing will be carried out at the Radiology
Installation of Pondok Indah Hospital, Jakarta. Design of distance sensor on medical device shown at Figure 3.

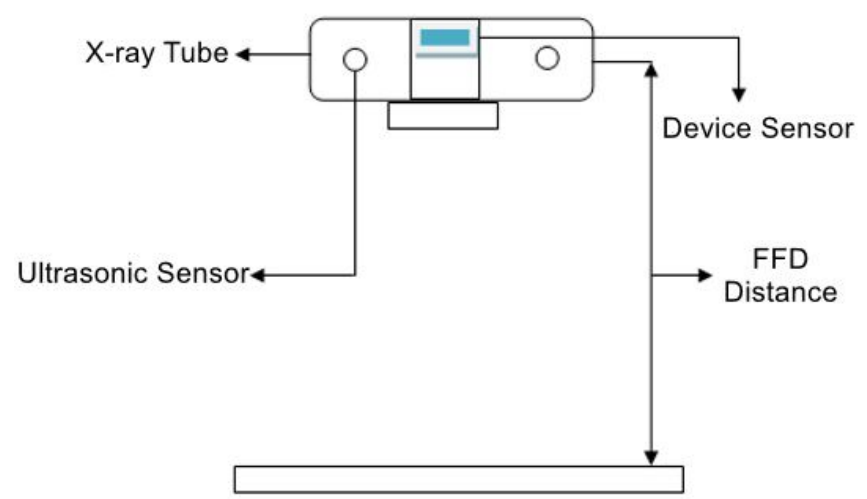

Figure 3: Proposed Device in Current Medical Device Design

\section{Block Diagram Design}

The following is a block diagram of a microcontroller-based distance measuring device consisting of an HC-SR04 sensor, a minimum circuit of an ATMega 8535 microcontroller, LCD (Liquid Crystal Display), keypad, LED, and buzzer. The block diagram design shown at Figure 4.

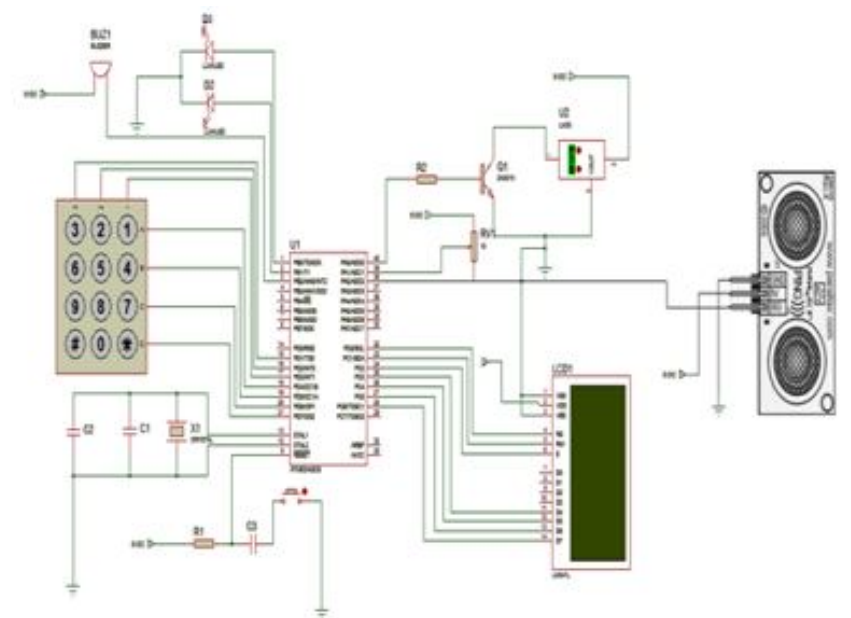

Figure 4: Design Schematic for Proposed Measuring Device

In general, according to Figure 4 above, the working principle of an automatic distance and angle measuring instrument using an ultrasonic sensor is initially an ultrasonic wave which is an ultrasonic signal with a frequency of approximately $40 \mathrm{kHz}$, which is sent from an ultrasonic transmitter, which is controlled by the ATMega8535 microcontroller. Then the ultrasonic signals sent (emitted) by this ultrasonic transmitter will go to the barrier or object, so that when the transfer of the ultrasonic sensor hits the barrier object, this ultrasonic wave will be reflected and received back by the reciver of the ultrasonic sensor for distance measurement, as well as also with the determination of the principle of the same angle with the measurement of distance. Once received and then processed in the microcontroller circuit then the results of the measurements will be used as 
Ari Murtanto et al., International Journal of Emerging Trends in Engineering Research, 10(2), February 2022, 53 - 58

data to be displayed on the LCD and turn on the buzzer alarm indicator and LED lights. This circuit has an ultrasonic sensor consisting of a transmitter and a receiver placed on the $\mathrm{X}$-ray tube, where to be able to reflect ultrasonic waves, the object of obstruction in this case is a cassette or bucky stand which is right in front of the X-ray tube.

The research procedure as described above can be briefly described in Figure 5.

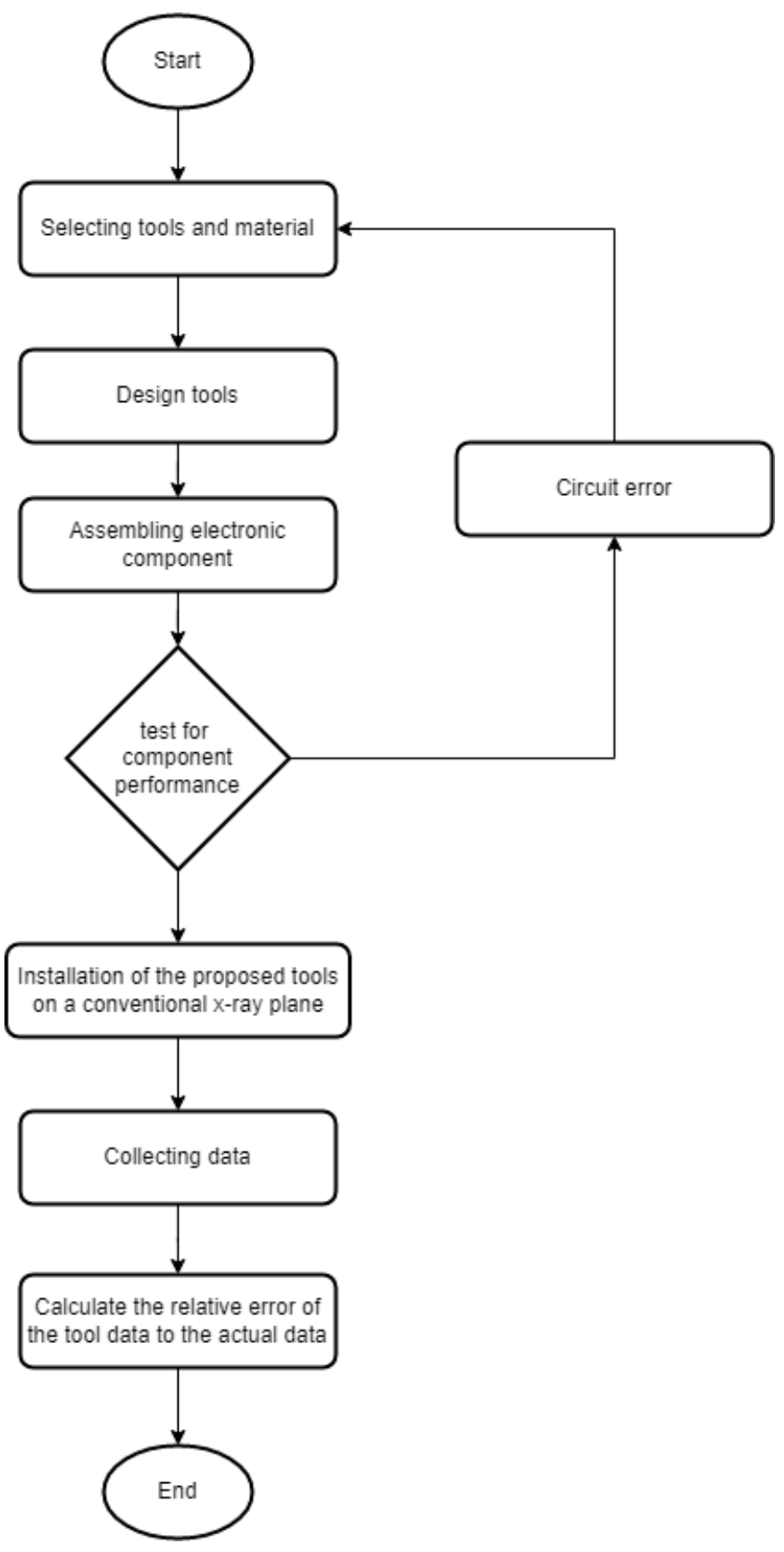

Figure 5: Research procedure flowchart

The following is a software on device workflow chart shown at Figure 6.

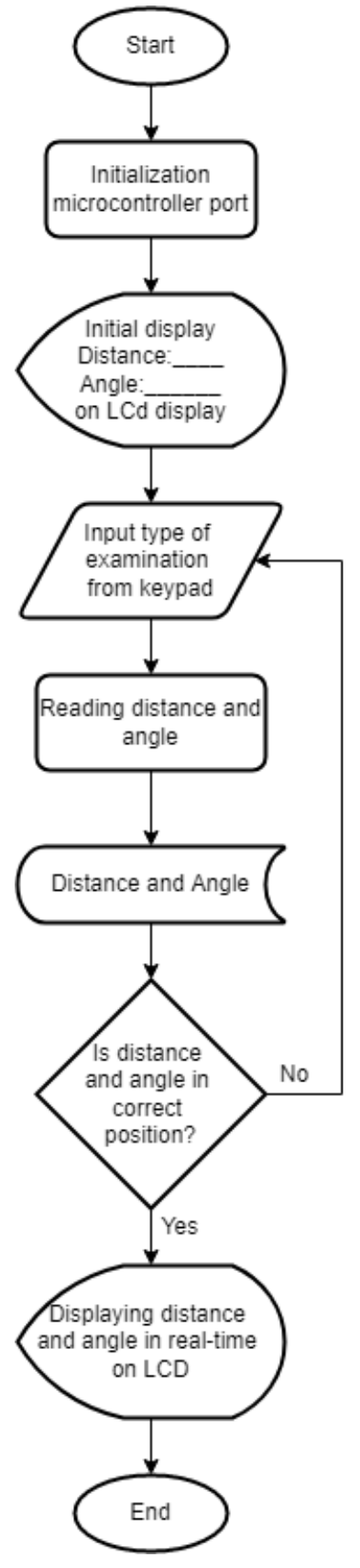

Figure 6: Software Flowchart of Proposed Device

\section{RESULTS AND DISCUSSIONS}

After carrying out the planning stage of making the instrument, collecting tools and materials that will be used to make an automatic distance and angle measuring instrument with an ultrasonic sensor, the tool can be seen in Figure 7. The function test of the tool will be carried out at the Radiology installation of Pondok Indah Hospital, Jakarta with actual distance data. For distance data collection, the author takes vertical and horizontal retrieval from a distance of 90 $\mathrm{cm}$ to $130 \mathrm{~cm}$. This measurement is carried out sequentially with $10 \mathrm{~cm}$ increments for each measurement from $90 \mathrm{~cm}$ to 
Ari Murtanto et al., International Journal of Emerging Trends in Engineering Research, 10(2), February 2022,53 - 58

$130 \mathrm{~cm}$. For testing the automatic distance set as well as the LED, as well as the Buzer, it is done by setting the automatic distance on the tool from $90 \mathrm{~cm}$ to $130 \mathrm{~cm}$ measurement with the addition of $10 \mathrm{~cm}$ for each test, while the angle data collection will be done manually.

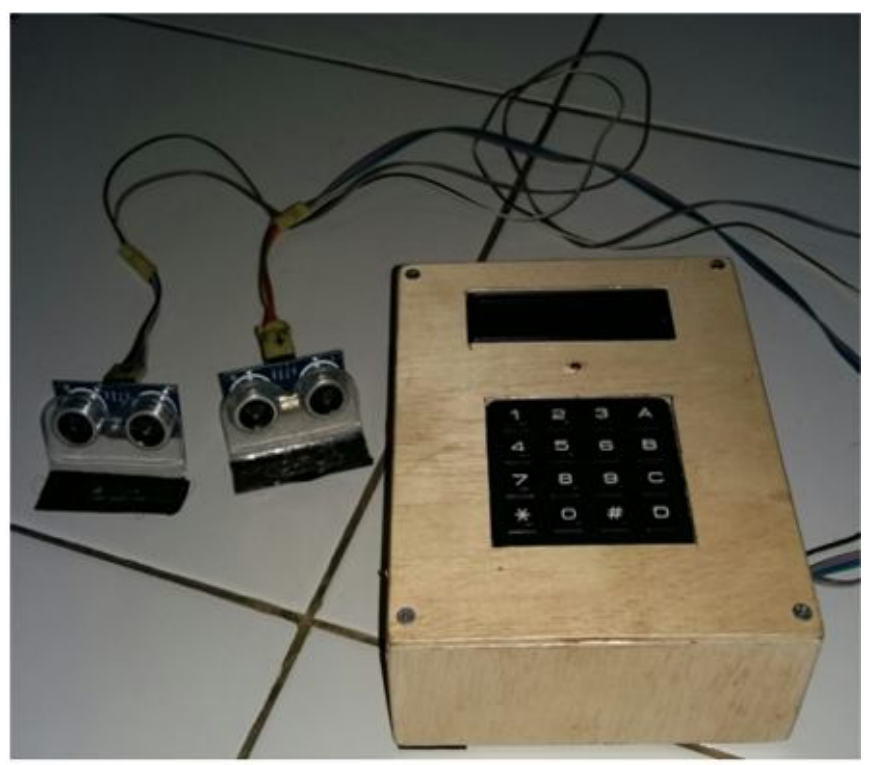

Figure 7: Product of Proposed Device

This proximity and angle sensor device will be attached to the vicinity of the conventional X-ray tube. The following is a picture of the sensor device that has been attached to the X-ray machine, which can be seen in Figure 8.

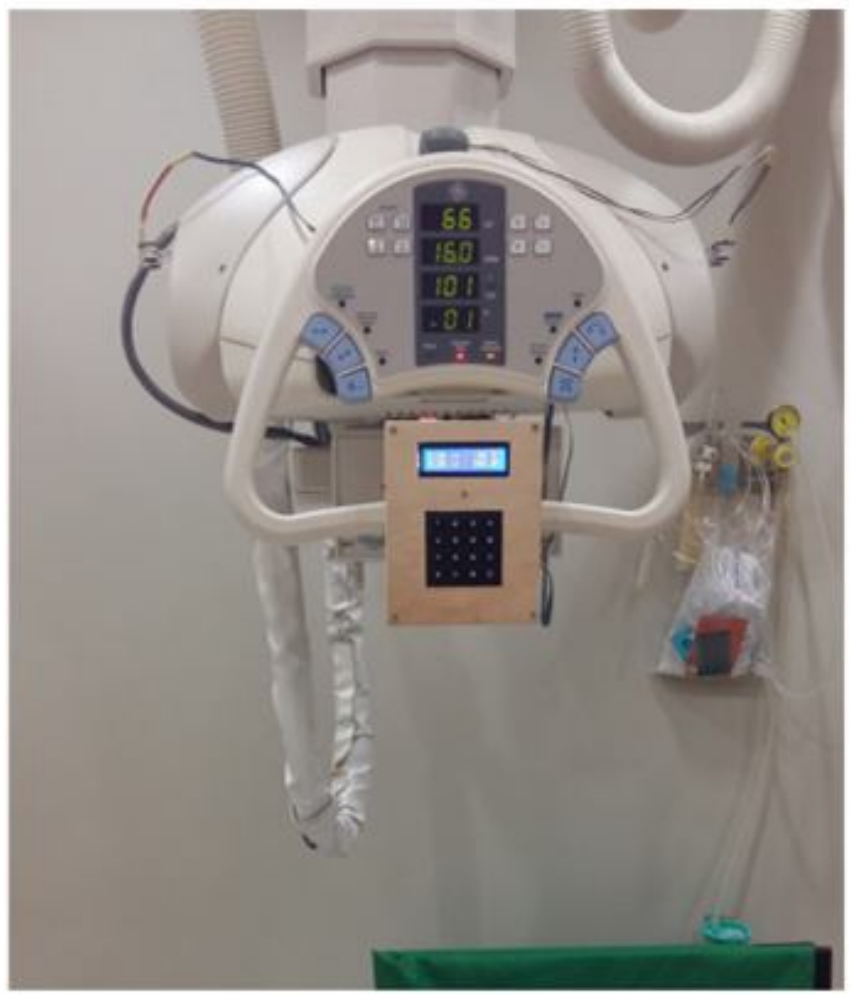

Figure 8: Proposed Device Attached at Medical Device

Vertical Distance Measurement

The relative error in this distance measurement can be seen in Table 1.

Table 1: Results of Relative Error and Vertical Relative Accuracy

\begin{tabular}{cccc}
\hline No. & $\begin{array}{c}\text { Distance } \\
(\mathbf{c m})\end{array}$ & $\begin{array}{c}\text { Relative } \\
\text { Error }\end{array}$ & $\begin{array}{c}\text { Relative } \\
\text { Accuracy }\end{array}$ \\
\hline 1 & 90 & $0.03 \%$ & $99.97 \%$ \\
2 & 100 & $0.10 \%$ & $99.90 \%$ \\
3 & 110 & $0.09 \%$ & $99.91 \%$ \\
4 & 120 & $0.09 \%$ & $99.91 \%$ \\
5 & 130 & $0.09 \%$ & $99.91 \%$ \\
\hline
\end{tabular}

Horizontal Distance Measurement

The relative error in this distance measurement can be seen in Table 2.

Table 2: Results of Relative Error and Vertical Relative Accuracy

\begin{tabular}{cccc}
\hline No. & $\begin{array}{c}\text { Distance } \\
(\mathbf{c m})\end{array}$ & $\begin{array}{c}\text { Relative } \\
\text { Error }\end{array}$ & $\begin{array}{c}\text { Relative } \\
\text { Accuracy }\end{array}$ \\
\hline 1 & 90 & $0.03 \%$ & $99.97 \%$ \\
2 & 100 & $0.10 \%$ & $99.90 \%$ \\
3 & 110 & $0.10 \%$ & $99.90 \%$ \\
4 & 120 & $0.10 \%$ & $99.90 \%$ \\
5 & 130 & $0.09 \%$ & $99.91 \%$ \\
\hline
\end{tabular}

Angle Measurement

The relative error in manual angle measurement can be seen in Table 3.

Table 3: Results of Relative Error and Relative Accuracy of Angle

\begin{tabular}{cccc}
\hline No. Angle & $\begin{array}{c}\text { Relative } \\
\text { Error }\end{array}$ & $\begin{array}{c}\text { Relative } \\
\text { Accuracy }\end{array}$ \\
\hline 1 & $10^{\circ}$ & $0,39 \%$ & $99,61 \%$ \\
2 & $15^{\circ}$ & $0,32 \%$ & $99,68 \%$
\end{tabular}


Ari Murtanto et al., International Journal of Emerging Trends in Engineering Research, 10(2), February 2022, 53 - 58

\begin{tabular}{llll}
3 & $20^{\circ}$ & $0,33 \%$ & $99,67 \%$ \\
4 & $25^{\circ}$ & $0,28 \%$ & $99,72 \%$ \\
5 & $30^{\circ}$ & $0,39 \%$ & $99,61 \%$ \\
\hline
\end{tabular}

Automatic Distance Set Test

Next test is testing with the distance set by pressing the number buttons listed on the tool. The data tested is from 90 $\mathrm{cm}$ to $130 \mathrm{~cm}$ with the addition of $10 \mathrm{~cm}$ each time the distance is set. After testing this distance set is in accordance with the distance set that has been pressed on the button, it can be seen in Table 4 below as follows.

Table 4: Results of Relative Error and Relative Accuracy of Angle

\begin{tabular}{cccc}
\hline No & $\begin{array}{c}\text { Distance } \\
(\mathbf{c m})\end{array}$ & Buzzer & LED \\
\hline 1 & 90 & on & on \\
2 & 100 & on & on \\
3 & 110 & on & on \\
4 & 120 & on & on \\
5 & 130 & on & on \\
\hline
\end{tabular}

Based on Table 1 we can see that the relative error value and relative accuracy obtained when the tool is installed vertically the largest relative error obtained is $0.10 \%$ with the best relative accuracy of $99.97 \%$ and in Table 2 when the tool is installed horizontally the largest relative error is $0.10 \%$ with the best relative accuracy is $99.97 \%$. Meanwhile, the angle measurement based on Table 3 obtained the largest relative error of $0.39 \%$ with the highest relative accuracy of $99.72 \%$.

\section{CONCLUSION}

From the research that has been done and seen from the processing results, it can be concluded, the relative error value and relative accuracy obtained when the tool is installed vertically the largest relative error is $0.10 \%$ with the largest relative accuracy $99.97 \%$ and when the tool is turned on pairs horizontally the relative error obtained is $0.10 \%$ with the greatest relative accuracy is $99.97 \%$. Meanwhile, in the angle measurement, the largest relative error is $0.39 \%$ with the greatest relative accuracy of $99.72 \%$.

\section{REFERENCES}

1. P. Muntner et al. Measurement of blood pressure in humans: a scientific statement from the American Heart Association, Hypertension, vol. 73, no. 5, pp. e35-e66, 2019.

2. J. K. Flake and E. I. Fried. Measurement schmeasurement: Questionable measurement practices and how to avoid them, Adv. Methods Pract. Psychol. Sci., vol. 3, no. 4, pp. 456-465, 2020.

3. N. Azman, F. Soleman, and I. Kusuma. Optimization $5 \times 195 \mathrm{kw}$ chiller compressor motor with etap, Int. J. Adv. Trends Comput. Sci. Eng., vol. 9, no. 5, pp. 7696-7703, 2020.

4. A. Z. Jacobs and $\mathrm{H}$. Wallach. Measurement and fairness, in Proceedings of the 2021 ACM Conference on Fairness, Accountability, and Transparency, 2021, pp. 375-385.

5. A. Rocchi, E. Santecchia, F. Ciciulla, P. Mengucci, and G. Barucca. Characterization and optimization of level measurement by an ultrasonic sensor system, IEEE Sens. J., vol. 19, no. 8, pp. 3077-3084, 2019.

6. M. Mihaljević, D. Markučič, B. Runje, and Z. Keran. Measurement uncertainty evaluation of ultrasonic wall thickness measurement, Measurement, vol. 137, pp. 179-188, 2019.

7. S. Bagavathy, P. R. Kumar, P. A. C. Raj, and B. Stalin, Frequency measurement through electric network analyzer for ultrasonic machining of steel, Mater. Today Proc., vol. 45, pp. 1775-1778, 2021.

8. N. Azman, A. Syarif, M.-A. Brahmia, J.-F. Dollinger, S. Ouchani, and L. Idoumghar. Performance Analysis of RPL Protocols in LLN Network Using Friedman's Test, in 2020 7th International Conference on Internet of Things: Systems, Management and Security (IOTSMS), 2020, pp. 1-6.

9. G. Kalifa et al. Evaluation of a new low-dose digital $x$-ray device: first dosimetric and clinical results in children, Pediatr. Radiol., vol. 28, no. 7, pp. 557-561, 1998.

10. J. Beatty et al. A new miniature $\mathbf{x} \square$ ray device for interstitial radiosurgery: dosimetry, Med. Phys., vol. 23, no. 1, pp. 53-62, 1996.

11. N. L. Arifin, H. Widiastuti, and A. Wibowo. Study on effect of source to film 
distance (SFD) on the radiographic images, in 2018 International Conference on Applied Engineering (ICAE), 2018, pp. $1-4$.

12. M. Q. E. Sousa, J. Pedrosa, J. Rocha, S. C. Pereira, A. M. Mendonça, and A. Campilho. Chest Radiography Few-Shot Image Synthesis for Automated Pathology Screening Applications, in 2021 IEEE International Conference on Bioinformatics and Biomedicine (BIBM), 2021, pp. 1791-1798.

13. M. Hirose, M. Ikeda, K. Ito, T. Ishigaki, and S. Sakuma. Considerations for standard chest radiography: the long film-focus distance technique, Nagoya $\mathrm{J}$. Med. Sci., vol. 55, no. 1-4, pp. 33-39, 1993.

14. P. C. Brennan, S. McDonnell, and D. O'Leary. Increasing film-focus distance (FFD) reduces radiation dose for x-ray examinations, Radiat. Prot. Dosimetry, vol. 108, no. 3, pp. 263-268, 2004.

15. V. Karami, M. Zabihzadeh, A. Danyaei, and N. Shams. Efficacy of increasing focus to film distance (FFD) for patient's dose and image quality in pediatric chest radiography, Int. J. Pediatr., vol. 4, no. 9, pp. 3421-3429, 2016.

16. V. Karami, M. Zabihzadeh, N. Shams, and A. Gilavand. Optimization of radiological protection in pediatric patients undergoing common conventional radiological procedures: Effectiveness of increasing the film to focus distance (FFD), Int. J. Pediatr., vol. 5, no. 4, pp. 4771-4782, 2017. 